\title{
Historical milestones in renal pathology
}

\author{
Jan J. Weening • J. Charles Jennette
}

Received: 11 April 2012 /Revised: 10 May 2012 / Accepted: 11 May 2012 / Published online: 3 June 2012

(C) The Author(s) 2012. This article is published with open access at Springerlink.com

\section{Introduction}

The history of renal pathology can be divided into two eras: one starting with the invention of the microscope and its application to renal tissue; the second with the introduction of the renal biopsy, which coincided with the development of electron microscopy and immunofluorescence microscopy that allowed the analysis of pathological changes in great detail with an eye for pathogenesis and pathophysiology. These two eras started in 1650 and 1950, respectively; an interval of no less than three centuries during which clinicians and pathologists struggled with a lack of clear understanding of the causes and evolution of renal disease. In concordance with the design of this series on the history of pathology, we focus primarily on the history of renal pathology before 1970 .

\section{The early phase}

Renal histology

The origins of renal pathology can be traced back to the earliest descriptions of the microanatomy of the kidney by

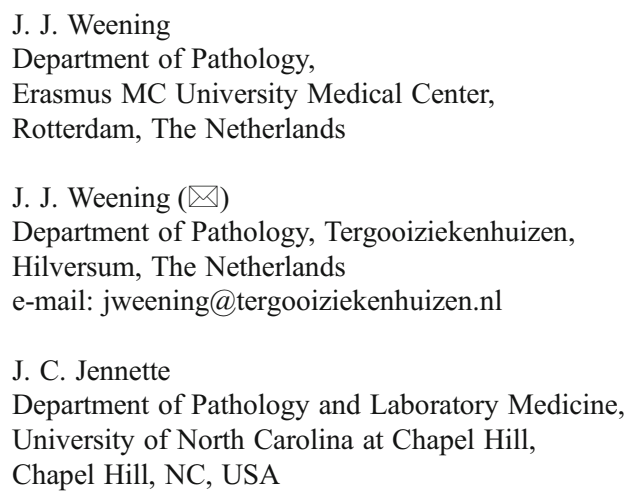

Marcello Malpighi in the year 1666 [1]. Based on his observations with the newly developed microscope, Malpighi (1628-1694; Fig. 1) hypothesized that the formation of urine took place in the kidneys through a filtering mechanism between blood and renal tubules [1]. Malpighi had studied medicine in Bologna and was professor in medicine first in Pisa and then at his alma mater and at the academy of Messina where he published his microscopic observations of various organs including the kidney. Before his illuminating studies, the relation between the kidney and the excretion of urine had been unclear and a subject of wild speculation as was true for renal function and disease in general.

The microscope was a new device at that time used by only a handful of researchers including Malpighi, Antoni van Leeuwenhoek, and Robert Hooke. Hooke had made an improved version of the instrument that was used by his Italian colleague. In combination with a talent for drawing and a sharp inventive mind, Malpighi was able to make giant strides forward, notwithstanding opposition from many colleagues at the time.

In spite of the seminal contributions of Malpighi based on the use of the microscope, his findings were completely overlooked by Giovanni Battista Morgagni who is regarded as the father of pathological anatomy. Morgagni was born in 1682 and lived and worked immediately after Malpighi, who had died in 1694. Morgagni was an anatomist and clinician and related postmortem findings to his clinical observations. He performed over 600 autopsies that form the basis for his major work De Sedibus et causis morborum per anatomem indagatis that was published in 1761 (Fig. 2) and had many reprints throughout Europe [2]. However, a complete understanding of the various diseases described in this book including those of the kidneys failed because of a lack of microscopic analysis, which Morgagni refused to rely on as an important tool. 


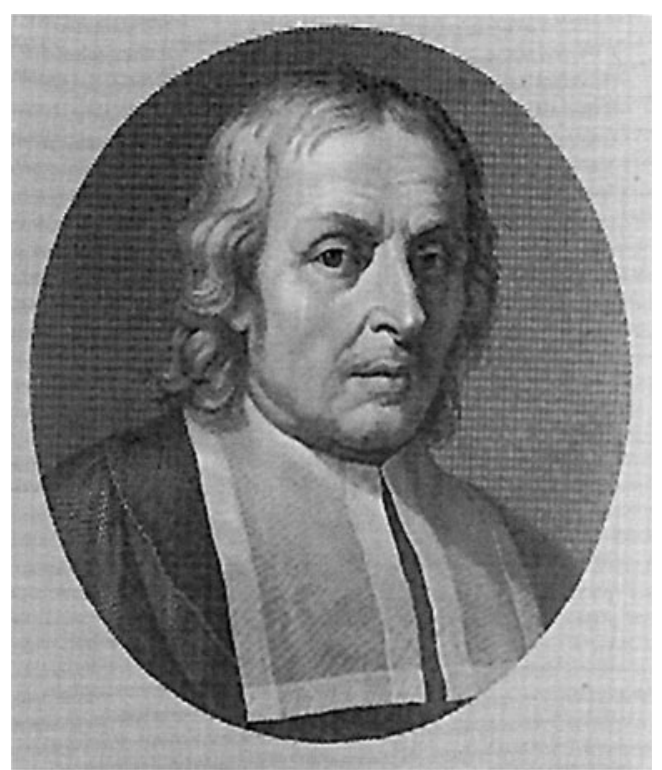

Fig. 1 Marcello Malpighi, approx 1660. From the Istituto e Museo di Storia della Scienza, Museo Galileo, Firenze, Italy

Malpighi's work was taken to a higher level by William Bowman, an English physician (1816-1892) who would later become a renowned ophthalmologist but devoted his early scientific life to the study of anatomy and physiology of the human body. One of his major contributions was the description of the components of the proximal part of the nephron with the periglomerular capsule (later named after him) as it is connected to the proximal tubule allowing the escape of filtrate produced by the glomerular capillary network (Figs. 3 and 4) [3].

\section{Clinical nephrology}

During the time of Bowman's early work, Richard Bright (1789-1858) together with John Bostock in England, Pierre Francois Rayer in France, and Friedrich Theodor von Frerichs in Germany studied patients with kidney diseases in great detail by correlating clinical symptoms and chemical derangements in blood and urine [4-7]. Pathology was limited to macroscopy and its contribution to diagnosis was therefore limited. Edema (dropsy as it was termed by Bright), hypertension, hematuria, oliguria, albuminuria, and uremia were quite well described but the underlying processes remained obscure. We now know that these symptoms can be caused by primary or secondary renal disease, affecting the glomeruli, the tubules, or the interstitium based on many different underlying events, which can only be recognized by microscopic analysis. The philosophy held at that time, however, was that in disease, functional alterations led to visible changes, and the latter, being secondary, were considered of less importance.

Richard Bright described three main macroscopic appearances of the diseased kidneys and tried to classify renal diseases accordingly [4] but admitted that he did not know whether these were mere stages of one disease or the faces of many different diseases from acute inflammatory to degenerative to sclerotic. Carl von Rokitansky, the famous pathologist from Vienna (1809-1878), took this to an extreme and used no less than eight classes of renal disease in albuminuric patients, one of which was renal amyloidosis [8]. Clearly, until microscopic analysis was applied to the pathological diagnosis of patients with various clinical syndromes, a rational classification of renal diseases was impossible.

Renal pathology (1850-1900)

The contribution of pathology was on its way, but it took many steps to achieve a level of refinement necessary to understand what is really going on in diseased renal tissues allowing a precise diagnosis of renal disease. Microscopic evaluation of renal tissue was facilitated by a number of technical advances in the mid nineteenth century. In 1837, Gabriel Valentin, a Swiss-German professor of physiology at Bern University, developed the technique of making thin tissue slides. Valentin described renal histology in patients who had died from massive proteinuria [9]. He observed no changes in the corpora Malpighia, but extensive accumulation of a grayish substance in the tubules soon to be recognized as fat, which subsequently led to the term lipoid nephrosis. In 1854 as a result of the invention of aniline dyes, more stains became available in addition to carmine, the only tissue stain that could be used until that year. Edwin Klebs, a pathologist who had worked with Virchow in Berlin, but had moved on to Switzerland and later to the US, introduced paraffin embedding in 1869 and used his improved histologic preparations to study renal
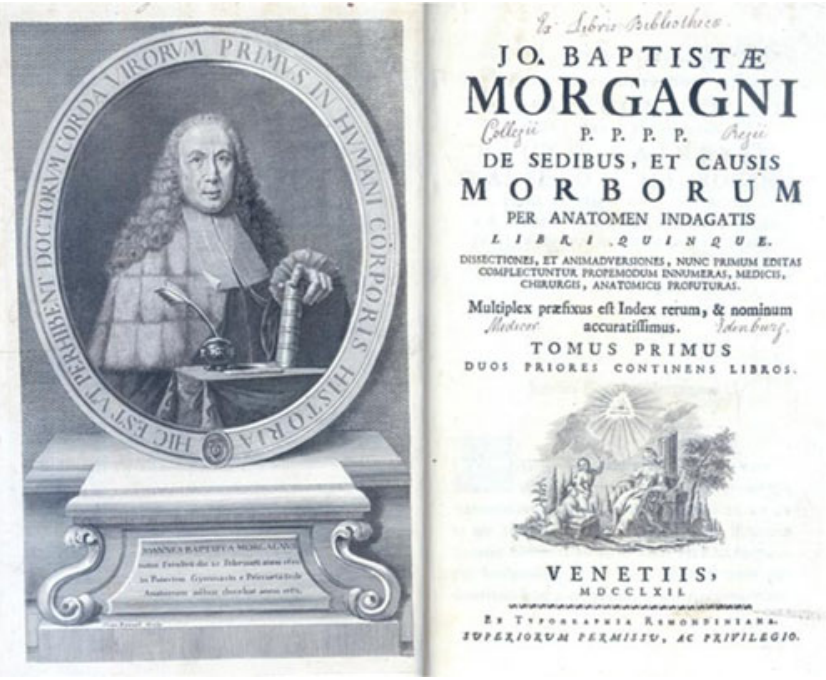

Fig. 2 Giovanni Baptista Morgagni's major work "DE SEDIBUS ET CAUSIS MORBORUM" (Ed. Venice, 1762). From the Bibliotheca Accademia Pugliese, Italy 


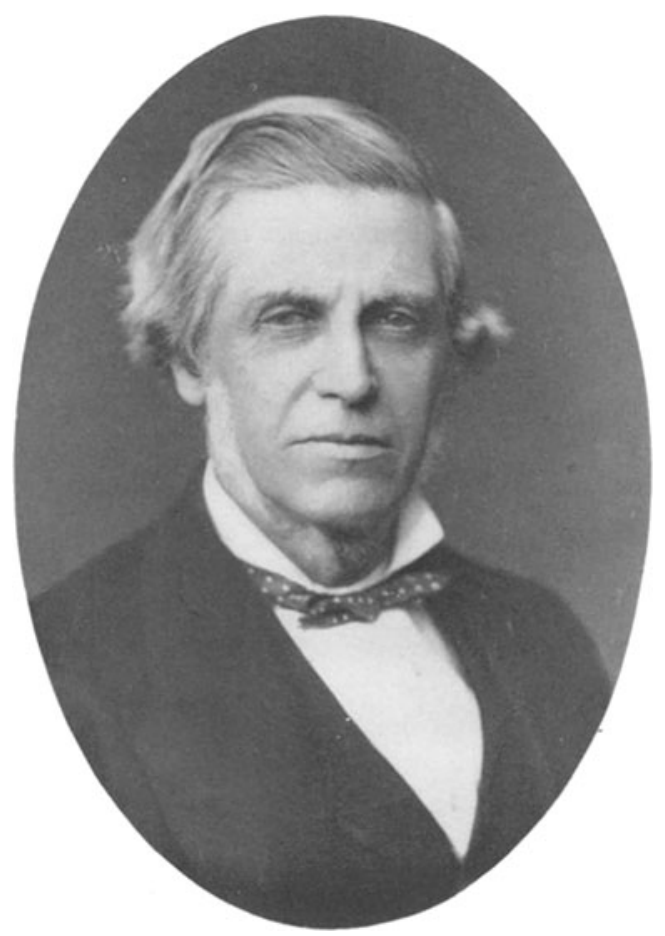

Fig. 3 Sir William Bowman, approx 1875, From the Science Photolibrary

disease. He coined the term glomerulonephritis in his pathology textbook [10].

The field then expanded quickly and from different sources evidence accumulated that pathological changes varied considerably between patients with similar "classes" of kidney disease. Based on microscopic analysis, several renal diseases were specifically identified including post-scarlatina glomerulonephritis, renal amyloidosis, and nephrosclerosis.

\section{Cellular pathology}

Important for the unraveling of tissue injury was the concept of cellular injury. The view of the cell as the basic unit of structure and function in the human body was first reported by Robert Remak [11], a Polish Jewish scientist, based on his observations that cell division led to cell renewal. In 1858 after first opposing this view, Rudolph Virchow applied it to his concept of cellular pathology [12], although he did not acknowledge the seminal work of Remak. The concept of cellular pathology was as valid for the kidney as for any other organ, but it took over a hundred years to unravel the characteristics of the variously differentiated cells of the nephron and their role in renal pathology.

\section{Cellular physiology}

Friedrich Henle (1809-1885) carefully dissected the microanatomy of the kidney (and many other organs) and discovered the tubular segment named after him as the loop of Henle [13]. He studied medicine at Heidelberg and Bonn, worked in anatomy in Berlin, and then became professor of anatomy in Zürich, Switzerland (Fig. 5). From there he went to Heidelberg to teach pathology, anatomy, and physiology. From Heidelberg, he published the Handbuch der systematischen Anatomie des Menschen [14], based on his concept that pathology and physiology were branches of one science. The cellular diversity of the tubular compartment became evident, ready to be unraveled by physiologists over the next century, starting with Carl Ludwig (18161895) and Claude Bernard (1813-1878), followed by Homer Smith (1895-1962), A. Newton Richards (1876-1966), Carl Gottschalk (1922-1997), and many others. Crucial for their studies were the contributions of chemists, among whom we can mention Donald van Slyke (1883-1971) and Lawrence Henderson (18781942), who developed techniques to allow microanalysis of plasma and urine.

Friedrich Theodor von Frerichs (professor of medicine at Berlin, 1819-1885) was perhaps the first to try to integrate clinical findings with microscopic analysis. This was taken further by his successor Friedrich von Mueller (Marburg, 1858-1941), and then by Volhard and Fahr [15].

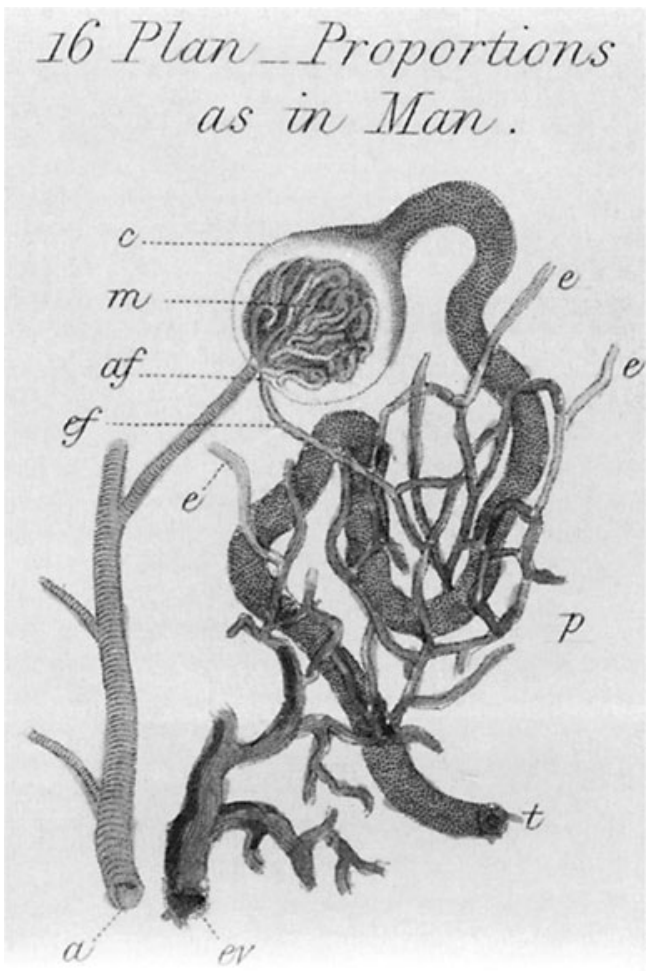

Fig. 4 Bowman's schematic drawing of the nephron. From The Science Photolibrary 


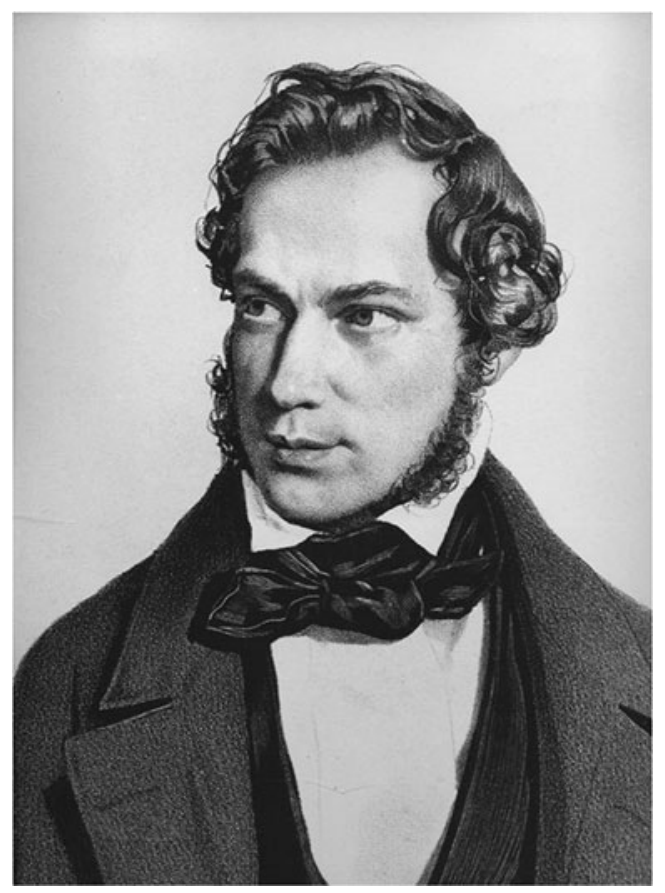

Fig. 5 Friedrich Gustav Jakob Henle (1809-1885). Henle worked in Berlin, Zürich, Heidelberg, and Göttingen. Robert Koch was his student and together they established the Henle-Koch postulates concerning the definition of disease-causing microbes. From Images from the History of Medicine

\section{Renal pathology (1900-1950)}

Theodor Fahr (1877-1945) was the first modern renal pathologist, documenting pathological changes in renal tissue with an exact eye for detail and relating these with the internist Franz Volhard to clinical expression of renal disease [15]. Fahr had trained in Giessen and received further training in Hamburg and Paris, where he worked with Ilya Metchnikoff, who in 1908 received the Nobel Prize for his work on phagocytosis. Fahr was made chairman of the institute of pathology at Hamburg University-Eppendorf in 1924 (Fig. 6).

The fruitful collaboration with Franz Volhard who worked at the university of Frankfurt-am-Main resulted in many publications, including the seminal Die Bright'sche Nierenkrankenheit, Klinik, Pathologie und Atlas (1914) [15] and his volume on the kidney in the series on pathological anatomy by Henke and Lubarsch [16].

In their classification of Bright'sche Nierenkrankenheiten, Fahr and Volhard classified renal disease into three major syndromes: the degenerative diseases (nephrosis), inflammatory diseases (nephritides), and chronic nephrosclerosis. Because of a lack of ultrastructural detail (the electron microscopy was not invented until 50 years later) and limited by only a superficial insight in renal inflammatory processes, the authors failed to recognize the glomerulus as the origin of proteinuria in patients with the nephrotic syndrome and placed too much emphasis on tubular reabsorption patterns coined lipoid nephrosis. However, by removing much of the confusion and controversies created by the publications of Bright and Morgagni, this new classification based on the combination of pathology and clinical expression of disease was a major improvement and became widely accepted.

Sir Arthur Ellis (1883-1966) published one of the earliest clinicopathologic studies of glomerular disease based on observations of the clinical courses of 600 patients with Bright's disease in the London Hospital including postmortem histological observations in 200 patients [17]. Ellis began his career in Toronto as a clinical chemist, trained in pathology at Western Reserve University in Cleveland, and eventually became a renowned professor of medicine at the University of London and Oxford before being knighted in 1953 for his contributions to the study of kidney disease. His multidisciplinary background in clinical chemistry, pathology, and internal medicine provided a unique perspective for making clinicopathologic correlations. He correlated clinical features, associated conditions (e.g., pharyngitis), blood and urine laboratory results, and histologic findings to propose two types of nephritis. Type I nephritis had an abrupt acute onset, often following an infection, with many but not all patients recovering. Type II nephritis had a more insidious onset characterized by edema and severe proteinuria. He described and illustrated with photomicrographs distinct patterns of glomerular injury that correlated with the clinical course, including glomerular hypercellularity with numerous neutrophils in

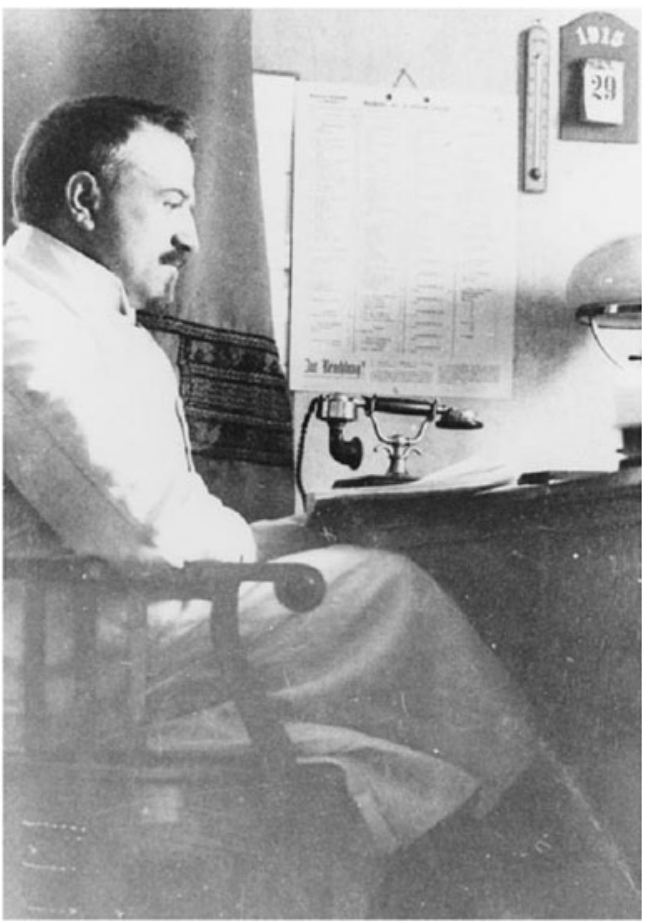

Fig. 6 Theodor Fahr as the director of the Institute of Pathology at the University of Hamburg. From Historical Archives of the University Hospital Hamburg-Eppendorf, Institute of Medical History, University Hamburg, Germany 
acute type I nephritis, fibrinoid necrosis, and crescents in severe type I nephritis and focal and nodular sclerosis in type II nephritis.

Further insight in the etiology and pathogenesis of renal disease was hampered by the fact that only autopsy material was available for analysis, mostly revealing no more than the endpoint of diseases, obscuring their kinetics and evolution. In addition, more knowledge was required in the field of genetics, cell biology, and immunology before renal diseases could be understood by pathologists and nephrologists as they are today. An important step forward was the introduction of experimental pathology. In a similar way as animal autopsies had preceded the precise study of the human body, laboratory animal experimentation allowed the early twentieth century scientist to induce renal disease and study its evolution over time. It permitted modulation of disease and the study of clinical symptoms. Several experimental models of renal disease were thus developed, preparing the field for a rational interpretation of renal biopsies in man.

\section{Experimental renal pathology}

Experimental renal pathology has contributed immensely to the understanding of renal disease for over a hundred years. In 1888, Theodor Tuffier (Paris, 1857-1929) studied the effects of partial renal ablation on renal structure and function [18]. This model would be explored in detail by many investigators in the last quarter of the twentieth century, documenting the role of intracapillary hypertension, glomerular cellular injury, and accelerating loss of nephrons, as a model for progressive renal disease [19-21].

A major impetus for the understanding of renal disease was derived from studies on infection and immunity. Infectious diseases had been by far the most important threat to health and society for ages and still were around the turn of the nineteenth to twentieth century. As of the nineteenth century, clinical and experimental works successfully started to reveal the basis of infection and immunity. Around 1900, the immune response was recognized as having a dark side causing disease by inflammation, anaphylaxis, allergy, and autoimmune reactions.

These early advances in immunology received much attention, were honored with Nobel prizes, and had their immediate impact on the renal field as on every other part of medicine. The Institut Pasteur in Paris was one of the centers of research in this field. It was there that Theodor Fahr worked with Metchnikoff and where kidney disease was studied in laboratory animals exposed to anaphylactic substances [22-24].

Also at Pasteur's Institute, W. Lindemann in 1900 developed a model of autoimmune glomerulonephritis by injecting rabbits with heterologous antiserum raised in guinea pigs against rabbit kidney [25]. This model was studied in depth by M. Masugi in 1933 [26] and was important in the new era that started in 1950. Between 1950 and 1960, serum sicknesslike glomerulonephritis was identified as the first immunemediated disease of the kidney caused by deposition of circulating immune complexes, a characteristic phenomenon in chronic infectious diseases and autoimmune diseases [27, 28].

\section{The modern era}

Renal pathology (1950-1970)

Three centuries had passed since Malpighi first observed the complex microanatomy of the renal glomerulus. Three centuries later, the almost simultaneous development of techniques to safely obtain renal tissue from a patient by means of a percutaneous needle biopsy and to analyze the tissue not only by light microscopy but also by electron microscopy and immunofluorescence microscopy suddenly provided the structural basis for diagnosis of the many different inflammatory and non-inflammatory, acute and chronic, relapsing and remitting, proteinuric and hematuric, hypertensive and nonhypertensive, and all other renal diseases that had been impossible to classify in an orderly fashion thus far. Within five decades, many questions were going to be answered, although several enigmas still remain today.

The renal needle biopsy was first used for clinical diagnosis of patients by Nils Alwall from Lund, Sweden in 1944. Alwall was successful in obtaining renal tissue by an aspiration technique from his first 13 patients but when 1 of them died from complications, he decided to no longer pursue the technique and did not publish his work until 1952 [29]. His efforts were continued by Paul Iversen and Claus Brun from Copenhagen who published their first series of renal biopsies in 1951 [30] and by Robert Kark from Chicago.

Robert M. Kark (Fig. 7), originally from Cape Town, a renowned rugby player while a medical student at Guy's Hospital, London, had developed an interest in nutrition during a fellowship at Harvard. In World War II, he used this expertise in nutrition to help develop K-rations and foiled a sabotage attempt on a plane to be used by Winston Churchill. Following the war, he became an expert on kidney disease at RushPresbyterian-St Luke's Medical Center in Chicago. Kark, who had met Iversen at a congress in Copenhagen in 1950, developed together with Muehrcke and Franklin a technique using the Vim Silverman needle (a cutting needle instead of an aspiration needle) in prone patients which proved to be much more successful than Alwall's procedure [31]. In collaboration with one of the first modern pathologists to specialize in renal pathology, Conrad Pirani, the Chicago group exploited the new development effectively, published widely, and established the Chicago unit as a teaching center for this new technique [31, 32]. The pathology world was at first skeptical, or should we 


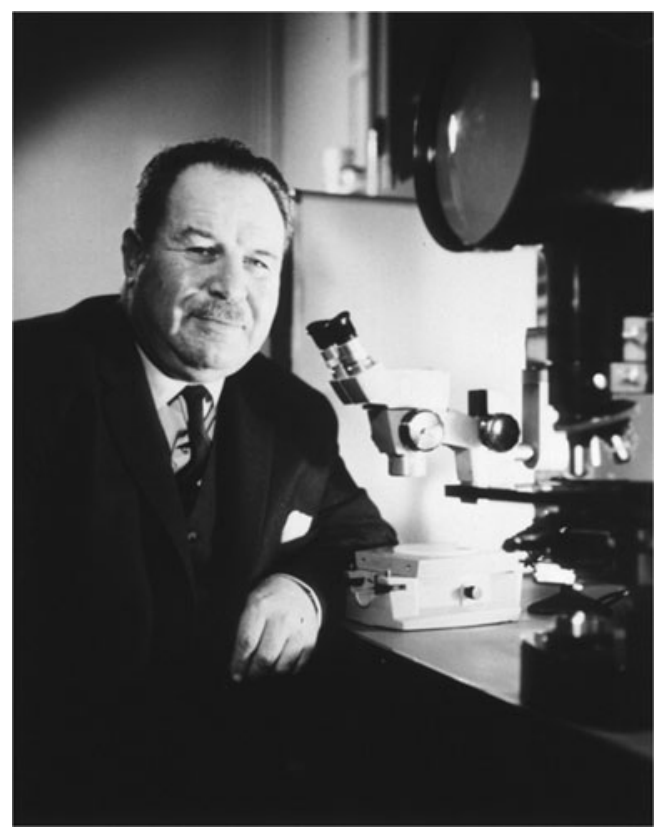

Fig. 7 Robert M. Kark who with Robert Muehrcke and renal pathologist Conrad Pirani pioneered the use of the renal biopsy in patient care. From Images from the History of Medicine

say hostile, to the idea of a tiny renal biopsy on which a full diagnosis was supposed to be made ("the smaller the biopsy, the more they want to know" is a frequently heard complaint in the practice of pathology). But several pathologists took up the challenge and successfully collaborated with nephrologists to advance the field of nephropathology.

Immunofluorescence microscopy as a technique to detect tissue-bound immune deposits had been developed by Coons and Kaplan in 1950 [33]. In 1955, Mellors first applied the technique to renal tissue [34]. Many renal diseases, particularly the various forms of glomerulonephritis, are antibody- and immune complex-mediated and the newly developed technique allowed for the first time observation of immune reactants that were contributing to the pathogenesis of many different forms of glomerulonephritis [35]. During the 1960s, Frank Dixon, Fred Germuth, and Robert McCluskey integrated the new knowledge about the pathogenesis of immune complex-mediated glomerulonephritis into concepts of diagnostic renal pathology.

Electron microscopy was new in the field as well and the first observations of ultrastructural changes in glomerular disease were published in 1957 [36].

The fenestrated endothelium, the multiple-layered glomerular basement membrane, the mesangium, and the intricate structure of the arborizing and interdigitating podocytes were discovered by thrilled pathologists staring through the binoculars of the first generation of electron microscopes [36, 37] (Fig. 8). Conrad Pirani in Chicago, Ramzi Cotran from Boston and Jacob Churg and Edith Grishman in New York were early pioneers in applying electron microscopy to renal biopsy diagnosis.
With the advent of the renal biopsy, and the application of better histology methods and electron microscopy, the understanding of the histopathology of renal disease developed rapidly at many centers around the world. During the 1950s, the Renal Association in London had monthly meetings at the Ciba Foundation where frequent discussions of renal biopsy findings and clinical correlations were discussed. This presaged the 1961 CIBA Foundation Symposium on Renal Biopsy in London, which was a landmark event in the maturation of the field of renal pathology. The session was chaired by Arnold Rich and pioneering renal pathologists who attended included A. Bergstrand (Sweden), R. Habib (France), R.H. Heptinstall (UK), R.B. Jennings (USA), H.Z. Movat (Canada), and C.L. Pirani (USA) [38]. Knowledge of renal pathology advanced to the stage that comprehensive textbooks became available to provide guidance to nephrologists and pathologists involved in the care of patients with kidney disease. Preeminent among these was Robert $\mathrm{H}$. Heptinstall's (Fig. 9) Pathology of the Kidney, first published in 1966 [39], which has cataloged the progression of knowledge in nephropathology through seven editions [40]. Robert H. Heptinstall began his medical career in London as a surgeon, but after World War II he trained as a pathologist. As a young pathologist at St. Mary's in London he collaborated with the renowned internist George Pickering on clinicopathologic studies of hypertensive

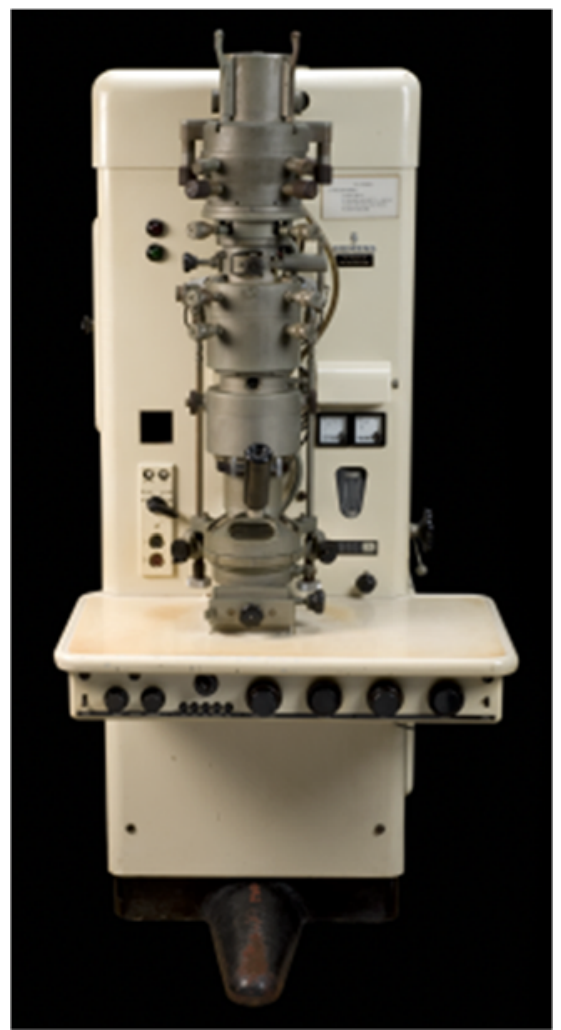

Fig. 8 Early generation electron microscope. From Siemens, 1955; Science Museum London, UK 


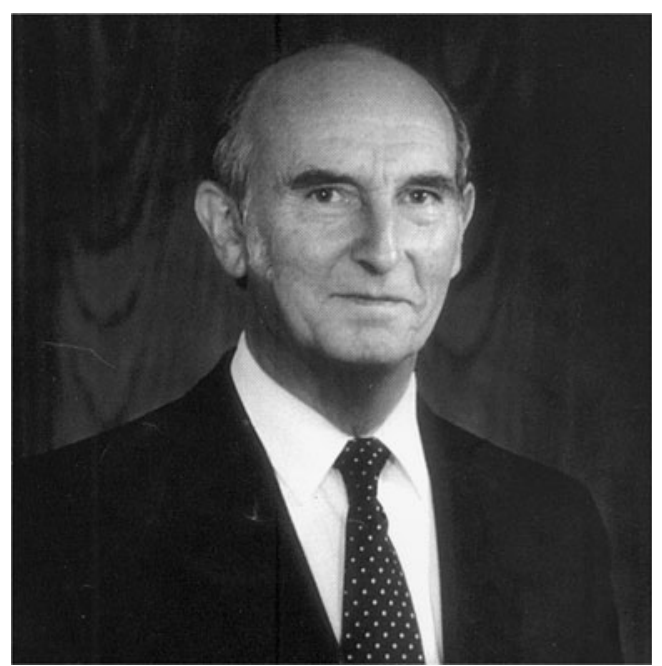

Fig. 9 Robert Heptinstall whose ground-breaking textbook Pathology of the Kidney influenced generations of nephropathologists and nephrologists. From Johns Hopkins University, Baltimore MD, USA

nephropathy, which was the beginning of a lifelong focus on renal pathology. With radiologist John Hodson, he worked on the pathogenesis of reflux nephropathy. In 1954 he did a fellowship at Johns Hopkins with Arnold Rich and Fred Germuth studying immune complex glomerulonephritis and in 1959 with Harry Goldblatt in Cleveland. He moved permanently to USA in 1960, briefly at Washington University in St. Louis and then at Johns Hopkins for the remainder of his illustrious career. At Hopkins he continued his research on hypertensive nephropathy and also studied pyelonephritis. His lasting legacy to renal pathology is the textbook that he first published in 1966 [39]. Several valuable books on renal pathology had been published already but his was the first to emphasize observations in renal biopsies rather than autopsies. The first edition primarily covered findings by light microscopy and electron microscopy, but the second edition in 1974 included immunofluorescence microscopy observations as well as a chapter by Robert McCluskey specifically devoted to immunologic mechanisms of renal disease [41]. These books by Heptinstall heralded the current era in renal pathology.

Renal pathology (1970 onward)

In the 1970s, the relatively few pioneers of renal pathology passed the baton to eager younger renal pathologists too numerous to name. Between 1970 and 2010, etiology, pathogenesis, clinicopathological correlations, and classification were established for renal diseases as diverse as lupus nephritis [42, 43], post-infectious glomerulonephritis [44], multiple forms of membranoproliferative glomerulonephritis [45], anti-GBM disease [46, 47], membranous glomerulopathy [48-50], IgA nephropathy [51-53], ANCA-associated vasculitis and glomerulonephritis [54-56], focal segmental glomerulosclerosis and other podocytopathies [57-59], hereditary renal diseases [47], hemolytic uremic syndrome [60], tubulointerstitial disease [61], renal injury in the kidney transplant patient [62], and many others (Table 1). Today's renal pathologists continue to build on the strong foundation laid by the pioneers of renal pathology to advance our knowledge of the pathology and pathogenesis of kidney diseases and to use this to improve the management of patients.

\section{Perspective}

In the almost 100 years since the pioneering clinicopathologic studies of Volhard the internist and Fahr the pathologist, tremendous advances have been made in our understanding

Table 1 Time table of seminal discoveries in renal pathology

\begin{tabular}{|c|c|c|}
\hline 1666 & The glomerulus & [1] \\
\hline 1842 & The nephron & [3] \\
\hline 1827 & Clinical renal syndromes & [4] \\
\hline 1914 & First renal histopathology classification & [15] \\
\hline $1900-1950$ & Experimental autoimmune glomerulonephritis & {$[25,26]$} \\
\hline $1950-1960$ & Renal biopsy & [29-32] \\
\hline $1950-1970$ & Immunofluorescence microscopy, electron microscopy & {$[33-37]$} \\
\hline 1960-present & Immune complex diseases, anti-GBM, lupus nephritis, post-infectious GN, IgAN & {$[27,28,42-47,51]$} \\
\hline 1975-present & Focal segmental glomerulosclerosis & {$[19-21,58,59]$} \\
\hline 1980-present & ANCA disease & {$[54-56]$} \\
\hline 1980-present & Membranous glomerulopathy pathogenesis & {$[48-50]$} \\
\hline 1990-2009 & Hemolytic uremic syndrome & {$[60]$} \\
\hline 1990-present & Podocyte pathobiology & {$[57,59]$} \\
\hline 1990-present & Classification of diseases of the transplanted kidney & {$[62]$} \\
\hline
\end{tabular}


of the pathology and pathophysiology of kidney disease and the care of patients with kidney disease. These advances have come as a result of intense collaboration between nephrologists and nephropathologists and have been facilitated by sharing new knowledge disseminated through national and international scientific societies, journals, and annual congresses in the field of pathology and nephrology. Advances in renal pathology also have been fostered in particular by the vitality of the Renal Pathology Society, which is international, and the Nephropathology Working Group of the European Society of Pathology. International collaborative efforts to benefit from advances in nephropathology have not been confined to economically well-off countries but also have been extended to the developing countries through the International Society of Nephrology [63]. Reviewing the history of renal pathology reveals how an entire field can only advance by the contributions of many, through implementing new technical developments, and fostered by the fortune of economic prosperity.

Acknowledgments The authors thank Dr. Joris Grond for the helpful comments.

Conflict of interest We declare that we have no conflict of interest.

Open Access This article is distributed under the terms of the Creative Commons Attribution License which permits any use, distribution, and reproduction in any medium, provided the original author(s) and the source are credited.

\section{References}

1. Malpighi M (1666) De Viscerum Structura execitatio anatomica. Bologna

2. Morgagni GB (1761) De Sedibus et causis morborum per anatomem indagatis. Venice

3. Bowman W (1842) On the structure and use of the Malpighian bodies of the kidney, with observations on the circulation through that gland. Philos Trans R Soc 132:57-80

4. Bright R (1827) Reports of medical cases selected with a view of illustrating the symptoms and cure of disease by a reference to morbid anatomy. Longman, Rees, Orme and Green, London

5. Bostock J (1803) Observations on the urine. London Med Phys J 9:349-355

6. Rayer PFO (1840) Traite des maladies des reins, vol II. Balliere, Paris

7. Frerichs FT (1851) Die Bright'sche Nierenkrankheitund deren Behandlung; eine Monographie. F Vieweg und Sohn, Braunschweig

8. Rokitansky KF (1846) Handbuch der allgemeinen pathologischen anatomie. Braumiller \& Seidel, Wien

9. Valentin G (1837) Repertorium fuer anatomie und physiologie. Huber, Bern

10. Klebs TAE (1870) Handbuch der pathologischen anatomie. August Hirschwald, Berlin, pp 644-648

11. Remak R (1855) Untersuchungen uber die Entwickelung der Wirbelthiere. G Reimer, Berlin
12. Virchow R (1858) Die Cellular-Pathologie in ihrer Begründung auf physiologische und pathologische Gewebelehre. A Hirschwald, Berlin

13. Henle J (1862) Zur Anatomie der Niere. Dieterichschen Buchhandl, Goettingen

14. Henle J (1876) Handbuch der Systematischen Anatomie des Menschen. Druck und Verlag von Friedrich Vieweg und Sohn, Braunschweig

15. Volhard F, Fahr T (1914) Die Brightsche Nierenkrankheit. Klinik, Pathologie und Atlas. Julius Springer, Berlin

16. Fahr T (1925) Die Pathologische Anatomie des Morbus Brightii. In: Henke F, Lubarsch O (eds). Handbuch der speziellen pathologischen anatomie und histology, Vol VI/1. Julius Springer, Berlin, p. $177-178,368-405$

17. Ellis A (1942) Natural history of Bright's disease. Clinical, histological and experimental observations. Lancet 1:1-7

18. Tuffier T (1889) Etudes experimentales sur la Chirurgie des Reins. G. Steinhill, Paris

19. Elema JD, Arends A (1975) Focal and segmental glomerular hyalinosis and sclerosis in the rat. Lab Invest 33:554-561

20. Hostetter TH, Olson J, Rennke HG, Venkatachalam MA, Brenner BM (1981) Hyperfiltration in remnant nephrons: a potentially adverse response to renal ablation. Am J Physiol 241:F85-F93

21. Olson J, Hostetter TH, Rennke HG, Brenner BM, Venkatachalam MA (1981) Altered glomerular permselectivity and progressive sclerosis following extreme ablation of renal mass. Kidney Int 22:112-126

22. von Pirquet CE, Schick B (1905) Die serumkrankheit. Deuticke, Vienna

23. Schick B (1907) Die nachkrankheiten der Scharlachs. Jahrb Kinderheilk 65:132-172

24. Richet C (1902) Des effets anaphylactiques de l'actinotoxine sur la pression arteriolle. Compt Rendu Soc Biol 54:837

25. Lindemann W (1900) Sur le mode d'action de certain poisons renaux. Ann Inst Pasteur 14:49-59

26. Masugi M, Tomizuka Y (1931) Ueber die spezifischen zytotoxischen veraenderungen der niere und der leber durch das spezifische antiserum zugleich ein beitrag zur pathogenese die glomerulonephritis. Trans Jpn Pathol Soc 21:329-341

27. Germuth FG Jr (1953) A comparative histologic and immunologic study in rabbits of induced hypersensitivity of the serum sickness type. J Exp Med 97:257-282

28. Dixon FJ, Feldman JD, Vasquez JJ (1961) Experimental glomerulonephritis. The pathogenesis of a laboratory model resembling the spectrum of human glomerulonephritis. J Exp Med 113:899-920

29. Alwall N (1952) Aspiration biopsy of the kidney, including a report of a case of amyloidosis diagnosed in 1944 and investigated at autopsy in 1950. Acta Med Scandinavica 143:430-435

30. Iversen P, Brun C (1951) Aspiration biopsy of the kidney. Am J Med 11:324-330

31. Kark RM, Muehrcke RC (1954) Biopsy of the kidney in prone position. Lancet 266:1047-1049

32. Muehrcke RC, Kark RM, Pirani CL (1955) Biopsy of the kidney in the diagnosis and management of renal disease. N Engl J Med 253:537-546

33. Coons AH, Kaplan MH (1950) Localization of antigen in tissue cells; improvements in a method for the detection of antigen by means of fluorescent antibody. J Exp Med 91:1-13

34. Mellors RC (1955) Histochemical demonstration of the in vivo localization of antibodies: antigenic components and the pathogenesis of glomerulonephritis. J Histochem Cytochem 3:284-289

35. Freedman P, Peters JH (1959) Immunologic aspects of renal disease. N Engl J Med 261:1275-81

36. Farquhar MG, Vernier RL, Good RA (1957) An electron microscope study of the glomerulus in nephrosis, glomerulonephritis and lupus erythematosus. J Exp Med 106:649-660 
37. Karnovsky MJ (1979) The ultrastructure of glomerular filtration. Ann Rev Med 30:213-224

38. Cameron JS and Hicks J. The introduction of renal biopsy into nephrology from 1901 to 1961: a paradigm of the forming of nephrology by technology. Am J Nephrol 17:347-358

39. Heptinstall RH Pathology of the kidney (1966) Little, Brown and Company, Boston

40. Jennette JC, Olson JL, Schwartz MM, Silva FG (2007) Heptinstall's pathology of the kidney. Lippincott Williams and Wilkins, Philadelphia

41. Heptinstall RH Pathology of the kidney (1974) Little, Brown and Company, Boston

42. Churg J, Sobin LH (1982) Lupus nephritis. Renal disease, classification and atlas of glomerular diseases Igaku-Shoin, New York pp 127-149

43. Weening JJ, D'Agati VD, Schwartz MM et al (2004) The classification of glomerulonephritis in systemic lupus erythematosus revisited. Kidney Int 65:521-530

44. Nasr SH, Markowitz GS, Stokes MB et al (2008) Acute postinfectious glomerulonephritis in the modern era: experience with 86 adults and review of the literature. Medicine 87:21-32

45. Sethi S, Fervenza FC (2012) Membranoproliferative glomerulonephritis, a new look at an old entity. N Engl J Med 366:1119-1131

46. Lerner RA, Glassock RJ, Dixon FJ (1967) The role of antiglomerular basement membrane antibody in pathogenesis of human glomerulonephritis. J Exp Med 126:989-1004

47. Hudson GB, Tryggvason K, Sundaramoorthy M, Neilson EG (2003) Alport's syndrome, Goodpasture's syndrome, and type IV collagen. N Engl J Med 348:2543-2556

48. van Damme BJC, Fleuren GJ, Bakker WW et al (1978) Experimental glomerulonephritis $n$ the rat induced by antibodies to tubular antigens. V. Fixed glomerular antigens in the pathogenesis of heterologous immune complex glomerulonephritis. Lab Invest 38:502-510

49. Debiec H, Guignonis V, Mougenot B et al (2002) Antenatal membranous glomerulonephritis due to anti-neutral endopeptidase antibodies. N Engl J Med 346:2053-2060

50. Beck LH, Bonegio RGB, Lambeau G et al (2009) M-type phospholipase A2 receptor as target antigen in idiopathic membranous nephropathy. N Engl J Med 361:11-21
51. Berger J, Hinglais (1968) Les depots intracapillaires d'IgA-IgG. J Urol Nephrol 74:694-695

52. Cattran DC et al (2009) The Oxford classification of IgA nephropathy: rationale, clinicopathological correlations and classification. Kidney Int 76:536-546

53. Roberts IS et al (2009) The Oxford classification of IgA nephropathy: pathology definitions, correlations and classification. Kidney Int 76:546-556

54. Davies DJ, Moran JE, Niall JF, Ryan GB (1982) Segmental necrotising glomerulonephritis with antineutrophil antibody: possible arbovirus aetiology? $\mathrm{Br}$ Med $\mathrm{J}$ (Clin Res Ed) 285:606

55. van der Woude FJ, Rasmussen N, Lobatto S et al (1985) Autoantibodies against neutrophils and monocytes: tool for diagnosis and marker of disease activity in Wegener's granulomatosis. Lancet I:425-529

56. Falk RJ, Jennette JC (1988) Anti-neutrophil cytoplasmic autoantibodies with specificity for myeloperoxidase in patients with systemic vasculitis and idiopathic necrotizing and crescentic glomerulonephritis. N Engl J Med 318(25):1651-1657

57. Pavenstaedt H, Kriz W, Kretzler M (2003) Cell biology of the podocyte. Physiol Rev 83:253-307

58. Churg J, Habib R, White RHR (1970) Pathology of the nephrotic syndrome in children. A report of the international study of kidney disease in children. Lancet 1:1299-1302

59. D' Agati VD, Kaskel FJ, Falk RJ (2011) Focal segmental glomerulosclerosis. N Engl J Med 365:2398-2411

60. Noris M, Remuzzi G (2009) Atypical haemolytic-uremic syndrome. N Engl J Med 361:1676-1687

61. Zeisberg M, Neilson EG (2010) Mechanisms of tubulointerstitial fibrosis. J Am Soc Nephrol 21:1819-1834

62. Solez K (2010) History of the Banff classification of allograft pathology as it approaches its 20th year. Curr Opin Organ Transplant 15:49-51

63. Weening JJ, Brenner BM, Dirks JH, Schrier RW (1998) Toward global advancement of medicine: the International Society of $\mathrm{Ne}$ phrology experience. Kidney Int 54:1017-1021 